\title{
ATILANO DE ZAMORA: SANTO, OBISPO Y PROFETA (SS. IX-X)
}

\author{
POR \\ ChARLES García ${ }^{1}$ \\ Universidad de Poitiers y CNRS \\ Centre d'études supérieures de civilisation médiévale
}

\begin{abstract}
RESUMEN
En este trabajo se analiza la documentación medieval que se conserva sobre san Atilano. Se hace singularmente hincapié en los momentos de la redacción de los diplomas y de las vitae con el propósito de poner en relación los textos con el contexto histórico en el que se fraguaron puesto que la literatura hagiográfica, como la mayor parte de la producción escrita medieval, fue generalmente una creación dinámica destinada a responder a las demandas sociales.
\end{abstract}

PALABRAS CLAVE: Hagiografía; san Atilano; milagros; reino de Oviedo-León.

\section{ATTILA OF ZAMORA: SAINT, BISHOP AND PROPHET (IX ${ }^{\mathrm{TH}}-\mathrm{X}^{\mathrm{TH}}$ CENTURIES)}

\author{
ABSTRACT \\ $\begin{array}{lr}\text { Recibido/Received } & 01-04-2018 \\ \text { Aceptado/Accepted } & 28-03-2019\end{array}$
}

This paper examines extant medieval documents about saint Attila. Particular attention is paid to the times when the charters and vitae were written, so as to place the texts in the historical contexts of their creation, since hagiographical literature, like most medieval written texts, was typically the result of a dynamic creative process responding to specific social imperatives.

KEY WORDS: Hagiography; saint Attila; miracles; kingdom of Oviedo-León.

Cómo CITAR este artículo / Citation: García, Charles. 2019. "Atilano de Zamora: santo, obispo y profeta (ss. IX-X)». Hispania Sacra 71, 144: 389-398. https://doi.org/10.3989/hs.2019.027

Contemporáneo por así decir de los mártires cristianos de Córdoba, ${ }^{2}$ Atilano (o Atila) de Zamora forma parte no obstante de la nómina de los santos confesores, en consonancia por así decirlo con los modelos de santidad vigentes en aquellos tiempos en el Occidente latino, el de los siglos IX y X. Es verdad que este personaje tenía poco que temer de las persecuciones religiosas en las comarcas en las que vivía entonces, las del noroeste de Hispania bajo dominación cristiana y no en el espacio de al-Ándalus como los mozárabes arriba señalados. A falta de poder contar con la muerte espectacular de un héroe martirizado, los hagiógrafos medievales de Atilano privilegiaron la puesta en escena de las reliquias y milagros del santo, resultando los textos,

1 charles.garcia@univ-poitiers.fr /

ORCID iD: https://orcid.org/0000-0003-1200-1521

2 Fernández Conde: 58-65. Sobre estos mártires mozárabes en la cuenca del Duero, cf. García 2014. para nosotros, como auténticas huellas creadoras y reveladoras de la ideología de su tiempo. Así pues, uno de los relatos que estudiaremos cruza, por ejemplo, de manera anacrónica, la actuación del santo con la de sus propias reliquias, en el mismo lugar pero con una distancia de cuatro siglos. De lo que no se puede dudar es que la mayoría de las leyendas diseñadas en la Edad Media acostumbran insistir en la protección que proporcionaban los restos de los santos, cosa que no sucede con Atilano por las razones que más tarde veremos.

Aunque fallen las reliquias en la exaltación de Atilano, lo cierto es que las narraciones que cuentan su historia se preocupan por incorporar dentro de un plan divinal a las colectividades involucradas en los relatos, caso de la de los habitantes de la ciudad de Zamora, o la de los cistercienses de Moreruela. De hecho, los textos comentan ampliamente el comportamiento de dichas comunidades para encarrilar en el debido camino espiritual a los fieles que se 
habían extraviado, y a ello se debe que en estas narraciones, el santo sea siempre el instrumento de Dios, su "amigo». En el relato del franciscano Juan Gil, el autor proporciona incluso la prueba de su sagacidad y oportunismo cuando considera la acción de Atilano de manera providencial, un hecho parecido a un gran acontecimiento, el de la invención por el santo de su propio cuerpo. Y otro tanto podría decirse del relato cisterciense de Moreruela destinado a legitimar y enfatizar la validez de la fundación monástica en aquel lugar.

Como es sabido, en la Edad Media, la hagiografía, como disciplina, era empleada como un medio de reflexionar sobre el pasado, la escritura y la interpretación de los tiempos y de los contemporáneos, incluso sobre el porvenir. Cuando dichas historias se escribían, lo que menos importaba a los autores eran los detalles de la vida del santo porque, en la concepción teológica de la historia que aquellos hagiógrafos tenían, los hechos importaban menos que su interpretación. Se podían adornar los acontecimientos o añadir nuevos detalles sin miedo a alterar el alcance básico del mensaje. En uno de los relatos, Atilano, preocupado por la duda de mantener su rango como pastor, y por ende por la fortaleza de su fe, se encontró ante un difícil dilema: abandonar el cargo pastoral o perseverar en la función clerical. Ahora bien, para los contemporáneos, ante una elección tan cruel, la misión principal que incumbía al obispo no dejaba de ser la de edificar al pueblo. En este sentido, la peregrinación expiatoria escogida por el prelado resultó siendo, para los autores de la historia, la mejor manera de servir la Iglesia como luego veremos.

Figura ejemplar para los miembros de su rebaño, la disposición del pastor zamorano al sacrificio tenía como objetivo reparar las faltas de su comunidad. Vistas así las cosas, la santidad de Atilano acaba resultando como una victoria a través de la expiación individual de los pecados de su pueblo porque la hagiografía nunca fue una tarea inocua. Pero antes de profundizar el estudio de este tema nos parece importante conocer el aspecto histórico de este personaje singular.

\section{El ATILANO HISTÓRICO SEgÚN LAS FUENTES DOCUMENTALES}

Para un hombre que vivió a horcajadas sobre los siglos IX y X, un momento muy particular para los reinos hispanocristianos sumidos en los "tiempos oscuros", la trayectoria individual de Atilano nos es bastante bien conocida gracias a la relativa abundante documentación literaria y diplomática de la época. ${ }^{3}$ Entre los múltiples testimonios conservados, empezaremos estudiando el de la Vita Froilanis atribuida al diácono Juan y redactada entre 910 y 920 . Este relato, cuya meta principal consiste en realzar la figura y las actuaciones de Froilán, obispo de León, proporciona abundantes informaciones sobre Atilano puesto que este fue durante largos años el compañero y, por así decir, el acólito de aquel. ${ }^{4}$ Conocida desde hace tiempo a pesar de no estar incluida en la Patrología Latina, la narración se ha beneficiado recientemente de una edición crítica muy esmerada. ${ }^{5}$ Según lo

3 Varios autores han recogido el conjunto de las fuentes documentales relacionadas con el santo. Entre las distintas recensiones, utilizaremos las de Carriedo Tejedo 1999 y el estudio más reciente y mucho más denso de Luis Corral 2009.

4 Canal Sánchez-Pagín 1993: 126

5 VF en apartado de Fuentes. que cuenta esta historia, Froilán, tras haber decidido dedicarse a la predicación itinerante en el entorno de la ciudad de León, se retiró en el recóndito monte Curcurrino donde Atilano se reunió con él. ${ }^{6}$ A pesar del alejamiento de ambos y de su vida de anacoretas, la fama de Froilán y Atilano no paró de crecer en el reino. Los dos habían fundado efectivamente un monasterio cerca de Veseo (Viseo), ubicado al sur del Duero, una gesta muy notable para la época. La actuación prestigiosa llegó a los oídos de Alfonso III, el cual rogó a los dos hombres que se presentaran en la corte de Oviedo, y fue así cómo, con el respaldo monárquico, ambos protagonistas prolongaron su obra pía fundando un monasterio dúplice en Tábara, el cual albergaba no menos de seiscientos monjes y un segundo, a orillas del Esla, enclavado en Moreruela de Tábara, en la margen derecha del río, que aglomeraba a doscientos religiosos. ${ }^{7}$ En recompensa por su dedicación y por su compromiso por ampliar la Cristiandad, Alfonso III los nombró obispos al alimón, no sin renuencias ${ }^{8}$ por parte de los beneficiados, pero con el beneplácito y la proclamación del clero y del pueblo, ${ }^{9}$ el día de Pentecostés del año 900, resultando Froilán instalado en la cátedra de León ${ }^{10}$ y Atilano en la de Zamora. ${ }^{11}$

Al margen de esta primera narración hagiográfica del siglo $X$, el nombre de Atilano figura sobre todo en algunos diplomas contemporáneos de la vita. Estos documentos están relacionados, casi todos ellos, con el episcopado del santo y se extienden concretamente de 907 a 919. Así por ejemplo, un diploma del monasterio de Celanova, si bien escrito en Zamora entre enero y mayo de 907, lleva la mención: «Sub Christi nomine, Adtila episcopus ibi presens fui». ${ }^{12}$ En este texto Atilano no aparece citado como obispo sino simplemente como testigo confirmante de la donación que hizo Alfonso III a favor del monasterio cercano de San Pedro de Tunis o Turris - actualmente de la Nave-. Dos años después, en abril de 909, con motivo de un intercambio de propiedades entre tres personajes Ilamados Sarracino, Falcón y Dulquito - probablemente presbíteros-, el nombre del santo surge de nuevo como testigo, pero ahora con el título

6 «Relinquid platea loca, adpetens per deserta et inaccessiuilia, fugiendo fabores et laudes hominum. Per rupes et abdita collium impiger ambulans, ut ubi inueniret locum quod solidariam et quietam ualenter duceret uitam remotus ab strepitu seculari, habens secum collegam sanctum Atilanem sacerdotem, cum quo uerbum diuinum meditabat frequens, peruenit ad kalcem montis. Heremi prospiciens et cunctaque peragrans ad alium montem, qui uocabulo est Curcurrini, construxit ibi cum collegam suum cellulam ad auitandum» VF: 580-581.

«Edificabit Taborense cenouium, ubi congregauit utrorumque sexum centies seni animas Domino seruientium. Tunc deinde prospiciens loca, ubi alterum edificaret cenouium, inuenit amenum et altum locum erga flumen Estole discurrente. Construxit ibidem cenouium, ubi congregauit ducentes fere monacos sub regulari norma constitutos» VF: 582.

8 Para escapar al cargo que se le imponía, Froilán insultaba al rey, proclamando que era un falso monje y que incluso tenía hijos.

9 «Quumque rex tamta uidisset in eum cresceret gratia sanctitatis, clamor populi adtollitur per multibus diebus Frolanem abbatem dignum esse episcopum in Legione ciuitatem nostrum» VF: 582.

10 Henriet 2009: 337.

11 «Tandem inuitus hordinatus est in Legione sede et collegam suum Atilanem in Zamorensem catedram. Diem sanctum Pentecostem pariter ambo consegrati sunt, honorem suscipientes sacerdotalem» VF: 582-583.

12 Sáez y Sáez 1996: 71; Andrade Cernadas et al. 1995: 589-590, doc. 429 
episcopal: «Atila episcopus confirmat» y «Attilanus episcopus confirmat». ${ }^{13}$

La referencia siguiente lleva la fecha del 15 de febrero de 911, día en el que Atilano firma un documento en León, ciudad en la que se encontraba entonces, en la curia - palatium regis- del rey García I cuando este entregó una serie de heredades al monasterio de San Isidro de Dueñas. ${ }^{14}$ En un diploma de fecha confusa, puesto que data del 1 de septiembre de 911 o de 912, establecido por Ordoño Adefónsiz de Galicia, el santo aparece otra vez citado como testigo junto a Nausto, a la sazón obispo de Coímbra: "Atila episcopus». ${ }^{15}$ De nuevo en 912, en el séquito de García I, Atilano aparece por vez primera como obispo titular de la sede de Zamora, en un diploma del monasterio de Eslonza escrito para certificar la donación de una villa que el rey y su esposa entregaban a dicha institución. ${ }^{16}$ Según las fuentes, parece ser que Atilano pasó los últimos meses del año 914 en el reino de Galicia acompañando a Ordoño II. El prelado rubrica en efecto en esta región dos diplomas a escasos días de intervalo, uno primero el 1 de diciembre ${ }^{17}$ y un segundo el 6 del mismo mes, ${ }^{18}$ con ocasión de la confirmación por parte del monarca y de la esposa de este, Elvira, en beneficio de la Iglesia de Santiago, de la propiedad de la villa de Lorenzana, cerca de León, y de otras heredades en la comarca del Bierzo.

Tres documentos de principios de 915, uno del día 29 de enero y dos del 30, nos informan que por entonces el obispo se hallaba en su ciudad de destino con motivo de lo que tiene visos de ser una asamblea episcopal —un sínodo-. Rubrica el primer diploma, en el que Ordoño confirmaba a la Iglesia de Santiago el giro territorial de inmunidad de seis millas, a las que añadía otras más. El texto, muy lapidario, se limita a indicar sencillamente: "Attila Zamorensi... Attila episcopus conf..${ }^{19}$ Por lo que a los otros dos diplomas se refiere, están relacionados con la donación de la villa de Corneliana a la catedral de Santiago a cambio de los quinientos «metcales» de oro que le había otorgado anteriormente Alfonso III. ${ }^{20}$ De forma inesperada para la época, es decir la de unos años caracterizados por huellas escritas parcas y lagunares, el santo obispo se manifiesta de nuevo a principios de 916. Una primera vez, el día 8 de enero, momento de la restauración de Santa Leocadia de Castañeda por el obispo - y también santo- Genaro de Astorga; ${ }^{21}$ una segunda, el 9 de enero, con ocasión de la donación que Ordoño II y su mujer Elvira hicieron al abad Servando en Valdecésar. ${ }^{22}$ Al año siguiente, casi el mismo día, 8 de enero de 917, Atilano aparece en otro documento de la catedral de León. ${ }^{23}$ Se trata de una

\footnotetext{
13 Mínguez Fernández 1976: 37-39, docs. 9-10.

14 Reglero de la Fuente 2005: 288, doc. 1, "Adilla episcopus conf.».

15 Carriedo Tejedo 1999: 348; Bouza Brey 1971: 277.

16 Ruiz Asencio y Ruiz Albi 2007: 50, doc. 1 (30 agosto 912), «concedimus terminum usque ad ipsam fontem qui est in ualle de Cascita... Sub Christi nomine, Attila, Dei gratia Zamorense sedis episcopus»; 53, doc. 2, "Attila, gratia Dei Zamorense sedis episcopus».

17 Carriedo Tejedo 1999: 349, «Attila Dei gratia espiscopus».

18 Lucas Álvarez 1998: 85, doc. 25, "Attila espiscopus conf.».

19 Ibid., doc. 25: "Attila espiscopus conf.».

20 Ibid., 86, doc. 26, "Attila episcopus conf.»; 88, doc. 27, "Attila episcopus conf.».

21 Cavero Domínguez y Martín López 1999: 70, doc. 13, «Sub Christi nomine Atilla Dei gratia episcopus».

22 Sáez 1987: 58, doc. 38, "Attila Dei gratia episcopus».

${ }_{23}$ Ibid., 66, doc. 41, "Sub Christi nomine, Attila, Dei gratia episcopus».
}

donación efectuada por Ordoño II en la que el rey entrega a Trasmundo y Recesvindo la aldea de Pardomino para que vivieran en el monasterio de San Andrés en ella edificado. Para terminar, en un documento posterior a la muerte del santo, puesto que fue escrito en 929 pero refiriéndose al año 916 como indica Fernando Luis, contemplamos el nombre de Atilano en torno a la consulta llevada a cabo por los obispos del reino sobre la fundación y dotación del monasterio de San Adrián y Santa Natalia de Boñar. ${ }^{24}$

La última cita documentada sobre Atilano es indirecta. Lleva la fecha del 10 de marzo de 922, por lo tanto, posterior a la defunción del obispo, y se encuentra inserta en un diploma de compraventa firmado entre un tal Nepociano y su mujer Gontina, por una parte, y el abad Servodeo y los monjes de san Pedro de la Nave, por otra. El objeto del diploma versa sobre la venta por los primeros de un robledo, de un valor de doce sueldos, enclavado entre Videmala y el río Aliste, o sea, al oeste de Zamora. Lo más interesante del texto es que cita un topónimo que ya llevaba entonces un lugar con el nombre del obispo recién fallecido: "Uendimus uobis ipso reuoreto ad integro per ubi uobis illum demarkauimus et coram testibus adsignauimus : de fonte de domno Atila episcopo et aquas currentes de auteiro qui est de occiente, deinde ad pinnas et ad fonte usque in termino de Sancto Petro". ${ }^{25}$

¿Qué conclusiones podemos sacar de este detalle, y por qué semejante topónimo? Nos encontramos ante dos opciones. O bien el solar en el que se encontraba el manantial era propiedad del obispo o de la Iglesia de Zamora, o bien, lo más probable, es que debamos poner en relación el nombre del lugar con la fama local del pastor zamorano, una fama consolidada al poco tiempo de su deceso. En efecto, como consecuencia de su anterior vida de ermitaño $-\mathrm{y}$ en cierto modo de profeta ${ }^{26}-\mathrm{y}$ de fundador de monasterios, no se debe obviar que Atilano fuera objeto de una devoción local poco después de morir, sin que ello supusiera que había alcanzado la categoría oficial de santidad, ${ }^{27}$ un grado que acabaría por conseguir varios siglos más tarde, bajo el pontificado de Urbano II, en 1092, según reza la tradición. ${ }^{28}$ Para terminar, el hecho de que se atribuyera su nombre a un manantial, no se opone a que se tratara de una voluntad de cristianizar una de las emanaciones acuáticas frecuentemente relacionadas con el paganismo, por añadido en una comarca en la que la densidad poblacional no debía de ser muy elevada a principios del siglo $X{ }^{29}$

\footnotetext{
24 Ruiz Asencio y Ruiz Albi 2007: 68, doc. 9 «Attila et uiuens Cixilanis siue cunctorum abbatuum».

25 Sáez y Sáez 1996: 79, doc. 16; Andrade Cernadas et al. 1995: 591-592, doc. 431.

26 "Les saints ascètes sont donc fils des prophètes [del Antiguo Testamento], selon un schéma que l'on peut qualifier de typologique» Henriet 2017: 8.

27 «Sanctum Attilanem» VF: 580.

28 «Esta falta de sincronía entre la devoción popular a un personaje considerado santo y el reconocimiento oficial de su vida ejemplar y "maravillosa" por parte de la Iglesia fue una de las características de la santidad altomedieval. Las iglesias importantes sacralizaban o mitificaban a sus fundadores, considerándolos como santos, un reconocimiento que muchas veces no traspasaba los límites de la propia diócesis» Fernández Conde 2008: 311, n. 77.

29 Martín Viso 2002: 74-75, 83-84.
} 
Como sabemos, la diócesis de Zamora ${ }^{30}$ fue establecida por Alfonso III en la figura de Atilano, sin necesidad de recurrir a una antigua tradición episcopal romano-visigoda, conformándola sencillamente mediante la sencilla translatio de un pasado prerromano heroico. Efectivamente, la Crónica de Alfonso III en su versión «rotense», contemporánea por consiguiente de Atilano, establece por primera vez la correspondencia documental entre Zamora y Numancia, ${ }^{31}$ esto en cuanto a la excusa histórica se refiere porque, en realidad, dicha creación obedecía como sabemos a las consideraciones políticas de entonces, las de la repoblación del territorio y las de la consolidación del espacio situado al norte del Duero. Atilano fue por lo tanto el primer obispo de Zamora con la misión, siempre supeditada a la autoridad del rey Alfonso III, de afianzar la joven civitas la cual, nada más nacer, se convirtió en uno de los principales baluartes militares del reino de Oviedo frente a al-Ándalus. La ciudad fortificada como nuevo centro de poder es por consiguiente el contexto en el que se deben interpretar las confirmaciones por Atilano de los diplomas regios, en conexión con los demás obispados del reino. Conviene sin embargo recordar que en aquellos años la diócesis zamorana no estaba aún territorializada, debiéndose conformar con el espacio de la propia ciudad y del entorno inmediato puesto que la influencia del obispo se reducía a los, muy escasos, sectores controlados directamente por la monarquía en aquella época. ${ }^{32}$ Atilano falleció probablemente en $919^{33}$ y tuvo una serie de sucesores en la cátedra episcopal hasta el año 986, fecha de una de las aceifas y de la conquista de Zamora por el belicoso Almanzor. ${ }^{34}$

\section{EL OBISPO, EL ANILLO Y EL PEZ}

Antes de iniciar el análisis del tema, conviene recordar que los relatos hagiográficos suelen atribuir la primacía al tipo de mártir o de confesor que ponen en escena, es decir, a la naturaleza edificante de la historia de estos en detrimento de la precisión histórica. Este enfoque intencional es lo que explica la abundancia de los lugares comunes y de los portentos, generalmente transmitidos de forma oral por la imaginación popular. El valor de estas narraciones estriba por lo tanto en el diseño de la obra y en la utilización que los autores hacen de sus fuentes. Es preciso por lo tanto leer estos relatos con una perspectiva doble, a sabiendas de que las lecturas espirituales e históricas deben ser situadas en su contexto, en concreto en el de la liturgia y el de la pastoral medieval. Como también es imprescindible saber que la santidad medieval debe ser puesta en relación con las expectativas que tenía aquella sociedad.

30 El presente trabajo no tiene en cuenta una referencia reciente, por haber sido escrito con anterioridad a dicha publicación: Historia de las diócesis españolas. Iglesias de Astorga y Zamora, coordinado por José Sánchez Herrero. Madrid: BAC, 2018.

31 «qui cum fratre Froilane saepius exercitum mouens, multas ciuitates bellando cepit, id est, Lucum, Tudem, Portugalem [...] Letesmam, Salmanticam, Numantiam quae nunc uocitatur Zamora...) (Bonnaz 1987: 45); Gil Fernández et al. 1985: 132, 206; Gil Fernández 2018: 410. 32 Garcia 2010.

33 Gutiérrez Álvarez 1997: 17, «C. 919 [HIC IACET SCS ATILANUS]».

34 Sánchez Herrero 1995.
Según cuenta la tradición, Atilano habría nacido en torno a 850 en Tarazona, una ciudad que se encuentra en el punto en el que confluyen tres reinos: Aragón, Navarra y Castilla. ${ }^{35}$ Procedente de una familia noble ${ }^{36}$-lugar común-, como lo indica la leyenda, el joven, cuyo nacimiento fue anhelado por sus padres durante largos años, y por fin conseguido a fuerza de rezos y de limosnas, se hizo monje a los quince años en un monasterio de su ciudad natal y, posteriormente, siendo ya sacerdote, ${ }^{37}$ residió durante algún tiempo en la abadía benedictina de Sahagún ${ }^{38}$ - un aspecto que tiene una importancia singular como luego veremos-. Entre tanto, los monjes cistercienses, que buscaban un pasado glorioso y con pátina temporal para su orden, sacaron provecho de la confusión procedente de la homonimia entre Moreruela de Tábara y Santa María de Moreruela (en la actualidad Granja), dos localidades que, pese a su nombre, se ubican a ambas orillas del Esla y que, además, tienen una cronología de ocupación diferente, para establecer, a comienzos del siglo XIII, la correspondencia entre las dos poblaciones atribuyendo a Froilán y Atilano la fundación de Santa María, en la margen izquierda, en el año 885, como si se tratara de una dependencia de la tabarense. ${ }^{39}$ El símil arraigó con tanta fuerza en la mente de la gente que las reliquias de Froilán que inicialmente habían pasado de León a Valdecésar, ${ }^{40}$ en la cordillera Cantábrica, para ser puestas a salvo de las aceifas de Almanzor, fueron posteriormente depositadas en Santa María de Moreruela (Granja) ${ }^{41}$ y, algo más tarde y de forma parcial, en la catedral de León. ${ }^{42}$ Este es por lo tanto el contexto, el de la búsqueda de orígenes remotos, en el que debe ser interpretado el texto del leccionario cisterciense de principios del siglo XIII que publicaría Enrique Flórez en el siglo XVIII, ${ }^{43}$ un autor que retomó, adornándolo - reescribiéndolo-, el texto de una original Vita sancti Attilani hoy perdida. ¿Qué informaciones nos proporciona el relato hagiográfico?

Resulta que un día, mientras Atilano meditaba sobre su vida, que por más señas estaba inmaculada de faltas y plenamente acorde con los preceptos cristianos, el santo valoró su trayectoria de forma distinta viéndola plagada de imperfecciones. Arrebatado por semejantes pensamientos, tomó la decisión de reparar sus antiguos errores imponiéndose a sí mismo una penitencia muy dura hasta que el Señor le perdonara sus pecados de juventud. Antes de iniciar el camino de la peregrinación, una expiación lamentada por su rebaño, dejó apuntadas las rentas que deberían ser entregadas por los clérigos a los pobres de Zamora durante su ausencia. Poco después, se vistió humildemente de peregrino y salió de la ciudad acompañado por un criado al que

\footnotetext{
35 Aldea Vaquero et al. 1972: 152.

36 «hujus enim parentes nobiles» VA: 463

37 «habens secum collegam sanctum Attilanem sacerdotem, cum quo uerbum diuinum meditauat frequens» VF: 580.

38 Escalona 1782: 27-28.

39 Calderón Medina 2008; Canal Sánchez-Pagín 1993: 124-125.

40 "Quidam autem ex ciuibus Legionis leuauerunt corpus Sancti
} Froilani Episcopi infra Pirenenos montes un Ualle Cesar, et posuerunt eum super altare Sancti lohannis Baptiste» Sánchez Alonso 1924: 66.

${ }^{41}$ Ibid.: "Quod postmodum Agarenorum metu in Ecclesia Sancti Petri occlusum, inde in Vallaem-Caesaris, post in Coenobium Moreruelense».

42 Ibid.: «et digne ad suam Ecclesiam Legionensem».

43 VA en apartado de Fuentes. 
poco después devolvió a su casa para seguir viajando solo. No obstante, al pasar por el puente que cruzaba el Duero, el cual estaba ubicado a proximidad de la iglesia de San Lorenzo, arrojó el anillo episcopal al río diciendo: cuando te vuelva a ver sabré a ciencia cierta que Dios me habrá perdonado. ${ }^{44}$ Hecho esto, tomó rumbo hacia Tierra Santa y sufrió mil calamidades hasta que llegó a Jerusalén, una ciudad que recorrió con gran devoción. Una vez cumplida la penitencia tuvo un sueño profético indicándole que había llegado el momento de regresar a su morada. ${ }^{45}$ Aplicando al pie de la letra las prescripciones del oráculo se presentó, siempre vestido con harapos, ante Zamora y pernoctó aquella noche en la hospedería de San Vicente de Cornú aledaña a la iglesia del Santo Sepulcro, la cual se encontraba en los arrabales de la ciudad. Al amanecer del día siguiente, el guardián que atendía la ermita se dirigió al palacio episcopal para solicitar un poco de limosna para poder comer. Allí le dieron tres peces pequeños, pero, al percatarse de que un pobre devoto lo estaba esperando en la hospedería, solicitó una cantidad mayor, y así fue como recibió un pez más grande a cambio de los tres pequeños. De regreso a la hospedería y mientras el ermitaño preparaba el almuerzo con su mujer, el santo, que se había puesto a lavar el pescado, encontró milagrosamente en sus entrañas el anillo que había arrojado al agua dos años antes, una sortija que se conserva y que todavía podemos contemplar. ${ }^{46}$

La alegría de Atilano fue inmensa tras el feliz hallazgo; se arrodilló y elevó las manos hacia el cielo en señal de agradecimiento. Por fin tenía entre sus manos la prueba de que el Señor le había perdonado. En aquel momento preciso, y como por milagro, las campanas de la ciudad se pusieron a tocar solas. Los zamoranos, incrédulos, procuraron comprender la causa de los repiques y encontraron la respuesta cuando el despensero del palacio se acordó del pobre peregrino, aquel para el que el ermitaño había pedido limosna. Informada de la anécdota, la muchedumbre se puso en camino hacia la hospedería y todos, pequeños y mayores, clérigos y habitantes de a pie, se presentaron ante el peregrino en andrajos el cual, como por milagro, resultó súbitamente vestido con unos magníficos atuendos episcopales. Feliz por ver de nuevo a su prelado tras una ausencia tan larga, la multitud se prosternó ante el santo y lo acompañó

44 «Quando te revidero, omnium delictorum meorum veniae certus ero» VA: 464. El tema del anillo arrojado al agua, y posteriormente recuperado, se repite con frecuencia en los relatos hagiográficos. Está presente en numerosas vitae, como por ejemplo la de Arnulfo, obispo de Metz en el siglo VII, uno de los antepasados de Carlomagno, tal y como la cuenta Paulo Diácono. En realidad, el tema es la recuperación de un estereotipo de la Antigüedad presente, por ejemplo, en Heródoto con relación a Polícrates de Samos. Sobre este aspecto remitimos a Martínez Ángel 2005: 209.

45 VA, p. 464: «Tandem per somnium oraculum accepit, ut ad suum Episcopatum jam reverti deberet». Sobre la interpretación de los sueños en la Edad Media, cf. Schmitt 2001.

46 El anillo de Atilano se conserva como reliquia en la iglesia de los Santos Pedro e Ildefonso de Zamora, así como el báculo, una pila y un peine litúrgico. Sobre las reliquias, cf. Yepes 1960: 386, «El anillo es muy delgado y tenía no más que un real de plata de peso ..., y está engastada en él una piedra turquesa algo mayor que un garbanzo. También guardan los zamoranos un peine de hueso, que dicen que servía a San Atilano, y el báculo a que se arrimaba, que es de palo, y hasta la pila en que se lavó el pez»; VA: 401-402; Fernández Duro 1882-1883: 218-230. en procesión hasta el palacio. ${ }^{47}$ Colmado por Dios y por su redil, Atilano prosiguió su tarea episcopal con mucho tesón hasta su fallecimiento. Era tal el entusiasmo de los zamoranos hacia él que lo sepultaron en la iglesia de San Pedro de la ciudad. ${ }^{48}$

Los autores del siglo XVIII, preocupados por no desagradar a los defensores del pensamiento «ilustrado», quienes imperaban en aquella la época, solían despreciar las viejas leyendas de santos a las que consideraban cargadas con un oscurantismo "maravilloso». Esta visión del espíritu llegó incluso a hacer dudar a los propios religiosos, supuestamente defensores de aquellas. ${ }^{49}$ Desde por lo menos Marc Bloch y su estudio sobre los «reyes taumaturgos», los hagiólogos saben que los relatos sobrenaturales, desconectados en apariencia de la realidad, son una fuente de primer orden para entender el funcionamiento del imaginario medieval $y$, por consiguiente, de la sociedad que lo sustentaba. Y lo mismo se puede decir de los milagros que encierran. Una vez estos postulados fijados, nos proponemos presentar una interpretación de la leyenda del milagro del anillo y el pez estudiándola como una construcción homogénea en cuanto a su dimensión simbólica se refiere. Así, mientras hoy día leemos dichos textos con un ojo escéptico - «racionalista»-, la gente de la Edad Media los veía como una señal del poderío divino al que nada podía detener puesto que Dios, que había creado el mundo, podía actuar a su gusto en los procesos naturales para modificarlos.

En calidad de santo, también hay que admitir que Atilano era visto en aquellos tiempos como un ser excepcional, próximo y a la vez diferente del hombre común. Actualmente se sabe que la función "política» de estos personajes medievales consistía en resolver las tensiones sociales en un lugar y momento concretos. Desde esta perspectiva, es preciso considerar que la principal misión del obispo de Zamora consistía en proteger a su grey, sobre todo a los más débiles, frente a los peligros que podían llegar desde fuera, pero también en aliviar las penas de los fieles en la vida diaria de estos. Además de ser santo, el relato que estamos comentando señala indirectamente que Atilano también era profeta ${ }^{50}$ y taumaturgo, dos dones que favorecían que fuese reconocido socialmente y escuchado por el público. ${ }^{51}$ Distinto por fin del hombre ordinario, el santo zamorano mantenía una relación privilegiada con el Creador, y lo cierto es que este vínculo singular fue el que le proporcionó unos poderes extraordinarios en el mundo terrenal, ${ }^{52}$ en una época en la que lo sobrenatural estaba muy presente en las consciencias de todos.

\footnotetext{
47 "et cum grandi gaudio et pompa in urbem eum deducunt» VA: 465.

48 Álvarez Martínez 1965: 106-107.

49 "Yo no quiero gastar el tiempo en disputas arbitrarias. En cosas de esta antigüedad ya dexo dicho, que se encuentran pocas demostraciones. Yo me holgara de tenerlas, para asegurar con firmeza la certidumbre de los Leccionarios [...] mientras los críticos no den pruebas positivas de ser falsos los hechos nada imposibles, asegurados por una tradición piadosa, y tan antigua, deberán sin mas ser despreciadas sus cavilaciones» Escalona 1782: 25.

50 «Ainsi, tout ce qui ressemble à de la prophétie n'est pas sainteté, mais aucune sainteté ne va sans esprit prophétique» Henriet 2017: 12.

51 Vauchez 1999: 1 R 17, 24.

521 Co $1,2$.
} 
Como muchos santos de la alta Edad Media hispánica, Atilano fue, durante su estancia en la cordillera Cantábrica, monje y ermitaño al mismo tiempo. Su fama, inferior por supuesto a la de su maestro Froilán, movió a que el diácono Juan lo evocara en la Vita Froilanis. El aislamiento al que se obligó estaba en ruptura con la sociedad y con los valores que la gobernaban, motivo por el que se hizo tan popular al tiempo que su compañero anacoreta. En las montañas inaccesibles de Curcurrino, ambos hombres estaban libres de las ataduras familiares y de las jerarquías monásticas, lo cual los volvía receptivos a Dios a quien se consagraban exclusivamente mediante sus oraciones. ${ }^{53}$ La recompensa divina por el ascetismo extremado y por el dominio de sí mismos se materializó en una forma de poder sobre la naturaleza y sus elementos. Convencidos de que vivirían en el yermo inhospitalario de la cordillera para siempre, accedieron a salir de aquel lugar cuando Alfonso III les rogó - suplicó (tópico)que se dedicaran a fundar monasterios. Un acto que acataron finalmente de buen grado debido al objeto espiritual de la empresa.

En la Hispania de la Alta Edad Media, como de hecho en otras muchas partes del occidente latino, la alianza entre la monarquía y el alto clero, o más bien la supeditación del segundo a la primera, ${ }^{54}$ así como el papel de los religiosos en la conversión del mundo rural y la asociación de ambos para fundar monasterios, favorecieron la aparición del modelo de la Adelheilige, es decir, el criterio del santo noble que aunaba en su propia persona el prestigio de un nacimiento de alta alcurnia, las virtudes del jefe y la piedad religiosa. El tipo más difundido de esta categoría fue el de los fundadores de abadías cuyos sucesores, al celebrar la memoria y exaltar los milagros de sus antepasados, buscaron acrecentar la proyección de su comunidad y la de sus bienhechores. En los relatos que estamos estudiando, el santo obispo zamorano poseía a la vez las cualidades del monje y las del pastor, y su perfección consistía en un género de vida mixta en el que los momentos dedicados a la liturgia y a la contemplación alternaban con fases de actividad al servicio de la realeza asturiana y de la Iglesia. En torno al año 900, el modelo de santidad sacralizaba el nacimiento, la autoridad y la riqueza, unas prerrogativas que en regla general eran las de la aristocracia que se estaba adueñando de la realidad del poder, sin que por ello dejara de desempeñar un papel creciente en la vida de la Iglesia por medio del monacato reformador. ${ }^{55}$

En lo tocante al obispo de Zamora, se puede deducir que era querido con mucho cariño por sus ovejas que se habían sentido abandonadas y desamparadas tras la partida repentina del pastor. A ello se debe que cuando la multitud recuperó al prelado, lo colmó de afecto para que no se volviera a marchar. La procesión de la muchedumbre que lo acompañó hasta el palacio es sumamente reveladora al respecto. Por añadidura, fue esta misma masa apasionada por aquel santo hombre la que lo enterró en la iglesia de San Pedro, puesto que el público deseaba tener el obispo a su lado como protector y para que las santas reliquias continuaran obrando después de su muerte en provecho

\footnotetext{
53 «anelauat spiritum semper in Deum» VF: 580.

54 Henriet 2007: 318-319.

55 Ayala Martínez 2008: 167-172.
}

del pueblo zamorano. Largo tiempo después del sepelio, a mediados del siglo XIII, se identificaría el cuerpo del santo difunto gracias a su incorruptibilidad, al delicioso olor que rezumaba y a la irradiación de la fuerza (virtus) encerrada en sus huesos porque Atilano también era miroblita.

Por lo que a la energía espiritual acumulada por el santo en las montañas, sería puesta con posterioridad al servicio de la comunidad zamorana, y esta es una de las principales razones por las que Atilano fue relativamente popular en la ciudad duriense entre los siglos X y XIII. Además, si consiguió proporcionar una cohesión sacra a su diócesis fue, siguiendo otro topos hagiográfico, porque era un forastero llegado de muy lejos: Tarazona; ${ }^{56}$ puesto que el alejamiento y la ausencia de lazos comunitarios eran considerados entonces como un factor de pacificación de los conflictos en el seno de una comunidad demasiado replegada sobre sí misma.

En la Edad Media se creía que el hombre y el mundo eran malos por esencia. Como contrapunto, y puesto que Dios simbolizaba el bien, había que incitarlo a que interviniera en los asuntos terrenales malogrados por los pecados. O sea que para entender el significado del viaje del santo a Tierra Santa hay que tener en cuenta este género de cosmovisiones. Fue porque se había sentido atormentado por sus acciones pasadas por lo que Atilano optó por emigrar y por lo que consideró que debía expiar sus faltas, auténticas o pretendidas. Como muchos santos - pensemos en Agustín-, Atilano había tenido en su juventud una vida licenciosa y pecadora antes de que accediera a la ascesis y a la espiritualidad -otro de los abundantes tópicos de la literatura hagiográfica-. Efectivamente, fue gracias a la ayuda de Dios con la que Atilano triunfó de la adversidad y merced a la que recibió dones proféticos que le permitieron barruntar que su aventura tendría un final feliz. Por lo que se refiere al entusiasmo popular generado por el milagro del anillo en el pez, puede ser explicado por la capacidad que el santo tenía de leer el porvenir, lo que le confería un inmenso prestigio y una gran autoridad entre sus admiradores. En este contexto, el santo local se convirtió en auténtico depositario del poder en el seno de la comunidad que le había confiado su destino. Después de su muerte, el culto y las fiestas que se organizaron con motivo del aniversario de su fallecimiento prolongarían y reavivarían el recuerdo de la edad de oro en la que todo había sido paz y prosperidad.

En el episodio del anillo arrojado al agua, simbólicamente una señal de humildad del obispo que no se sentía autorizado a seguir con su carga, no se vislumbra ningún mensaje explícito inmediato y solo, al final del recorrido, será cuando la historia cobrará una explicación: la del triunfo del bien sobre el mal. Gracias a Atilano, la comunidad se recompuso por medio de ceremonias y ritos como el de la procesión o el de la peregrinación a Tierra Santa, sin perder de vista por lo demás que el viaje a Jerusalén es un ejemplo de peregrinaje escatológico. Se trata propiamente de un recorrido penitencial que recuerda la imitación de Cristo, cuando no una llamada al martirio. Lo cierto es que a principios del siglo $X$, en el contexto del reino astur, el iter lerosolimitanum era visto como un fenómeno con fuerte tensión escatológica parecido al que se puede contemplar en los beatos contemporáneos.

\footnotetext{
56 Lucas, 4, 24: «Que ningún profeta es aceptado en su propia
} tierra». 
Volviendo al relato, la leyenda nos dice que Atilano cruzó el río para salir de la ciudad, lo que significa que tomó la ruta del sur y que volvió por el mismo camino puesto que pasó la última noche en la capilla-ermita de San Vicente de Cornú ubicada al sur del Duero. Algunos añadidos, posteriores a la redacción original, cuentan que el puente se desmoronó nada más pasarlo Atilano para impedir que los mahometanos penetrasen en la ciudad. ¿Qué explicaciones se pueden sacar de estas afirmaciones? Señalemos, para empezar, que Atilano optó por atravesar al-Ándalus en un momento de gran peligro para los cristianos, lo que no podía sino realzar su elección. ¿¿De qué peligro se trata?

El día 10 de julio -o de junio- de 901, o sea, un año exacto después de la entronización de Atilano como obispo, una de las mayores batallas de la "Reconquista», según Claudio Sánchez-Albornoz, se desarrolló ante las murallas de Zamora: la Jornada del foso, para los cristianos, o día de Zamora para los musulmanes. ${ }^{57}$ Aquel día, una formidable armada compuesta por bereberes fanatizados fue derrotada por Alfonso III con la ayuda del mítico Bernardo del Carpio. En aquellos combates, el puente que había cruzado el obispo desempeñó un papel determinante. ${ }^{58} \mathrm{El}$ caudillo de aquel ejército, el príncipe y mahdi Ahmad Ibn al-Qitt, fue capturado y su cabeza fue colgada en una de las puertas de la ciudad que desde entonces lleva su nombre: Balborraz ( bab al ras). ${ }^{59}$ Si bien es cierto que las crónicas árabes y cristianas no citan a Atilano en tan heroico episodio, resulta difícil imaginar que el santo no desempeñara, como pastor, un papel de galvanización y de cohesión de la población durante el ataque de los agarenos.

Así pues, el milagro medieval del anillo dentro del pez debe ser interpretado en clave antropológica como un signo, es a la vez una teofanía - manifestación de Dios- y una advertencia o lección para los hombres. Debe ser visto como un elemento destinado a la edificación del cristiano y de la Iglesia. El tema del pez como símbolo es constitutivo del cristianismo. El de Atilano se parece, de forma mimética, al de Tobías utilizado como figura de la salvación desde el siglo III. Esta figura está asociada, por supuesto, al símbolo del icthius, un acróstico griego que retoma los títulos de Cristo. A partir de este símil se desarrolló una amplia homilética en el Occidente cristiano, se trata de una exégesis cristológica pero también eucarística y bautismal en el caso de Atilano. En este sentido y mediante este ejemplo, estamos en el corazón de la pesca redentora que realza la obra del pescador. ${ }^{60}$

En los relatos que estamos analizando, nos encontramos por lo demás con la presencia de varias ermitas en la vida de Atilano: la del yermo de las montañas cantábricas, la de

57 Sánchez-Albornoz 1972-1975: 583; Mínguez Fernández 1995.

58 "Sobre la cinta de plata que los muslimes llamaban "Río Grande", sólo un viejo y caduco puente, testigo pétreo de la gloria romana, se alzaba como un símbolo entre la Europa progresiva y el África salvaje. En el viejo puente hubo de comenzar el combate» Sánchez-Albornoz 1972-1975.

59 «Los cristianos, después de apoderarse de toda la máquina de guerra de Ahmad y saquear todo el campamento, que le proporcionó un rico botín, cortaron la cabeza de lbn al-Qitt, ese príncipe omeya que se hizo pasar en vida por el Mahdi. El rey Alfonso ordenó que esta cabeza estuviera colgada en la puerta de Zamora» Maíllo Salgado 1990: 29; según el relato de Ibn Hayyân (987/8-1076).

60 Doignon 1976.
San Vicente de Cornú y aquellas, presuntas, en las que debió albergarse el santo durante su viaje de ida y vuelta a Tierra Santa. Tales ermitas forman parte sin lugar a dudas de una red de santuarios taumatúrgicos que daban cobijo a los santos y hacia los que acudía la gente para recibir ayuda y protección en las pruebas de la vida. En un registro parecido, es necesario interpretar las reliquias del santo, como el anillo, el báculo y el peine, en tanto que instrumentos de una pastoral destinada a erradicar el folklore pagano de una población alejada durante largos años de la Iglesia, como hemos observado más arriba al hablar del manantial. En esta línea, se puede por lo tanto afirmar que las ermitas y las reliquias participaban en el afianzamiento y en la difusión de la santidad cristiana, y no es por azar si uno de los escasos lugares de la ciudad que todavía recuerda a Atilano es el cementerio - actualmente municipal- edificado contiguamente a la capilla de San Vicente de Cornú.

El milagro anular aclara finalmente nuestro análisis sobre el carisma profético de Atilano, un santo que, en su calidad de obispo, proclamó la doctrina cristiana y los mandamientos divinos. En la primera epístola a los corintios, san Pablo enumera los nueve dones de la gracia divina ${ }^{61}$ por medio de la cual la presencia del Espíritu se manifestaba en los bautizados como lo recuerda la visión de las palomas en la Vita Froilanis:

Cum ille pernoctasset in oratione, uidit intempesta nocte claritatem splendoris refulgente duas columbas uicissim zelo uolitantes, una flameo calore et alia niueo candore, siui propinquantes. Dum stupore perterritus eas ad se ueniendo aspiceret, concite in ore eius intraberunt. Una exurere eum cepit, altera demulcere animum sensit. Qui non credat tali uisione Spiritu Sancto fuisset repletus ? ${ }^{62}$

Atilano, como indica el apóstol de los gentiles, tenía la capacidad de leer en los corazones y la de adivinar las cosas ocultas. Con el episodio del anillo, da la prueba de tener dones proféticos, los de un santo que estaba destinado a guiar a los zamoranos por el buen camino: aquel que les llevaría a la salvación. La autoridad del santo procede pues del don de clarividencia del presente y del porvenir, sin dejar por ello de ser un sacerdote legitimado en su función por la institución eclesiástica. En realidad, si Atilano cumple un milagro es también por los poderes que la Iglesia le había conferido mediante el sacramento de la ordenación. En él, el poder sobrenatural no se oponía al poder institucional, sino que ambos se compenetraban.

\section{EL CUERPO RECUPERADO DEL SANTO}

Después de que su memoria se perdiera durante dos siglos y medio, el cuerpo de Atilano reapareció milagrosamente en mayo de 1260 durante el episcopado de don Suero Pérez de Velasco. ${ }^{63} \mathrm{El}$ eclipse se debe a que, tras la

611 Co 12 , 8-10: «A cada cual se le otorga la manifestación del Espíritu para provecho común. Porque a uno se le da por el Espíritu palabra de sabiduría; a otro, palabra de ciencia [...] a otro, carisma de curaciones, en el único Espíritu; a otro, poder de milagros; a otro, profecía; a otro, discernimiento de espíritus».

62 VF: 579-580.

63 Linehan y Lera Maíllo 2003. 
conquista de Zamora por Almanzor, la diócesis se encontrara sin obispo durante el siglo XI, y no fue hasta 1121, a finales del reinado de Urraca, cuando el territorio encontró un titular realmente autónomo para la cátedra con Bernardo de Périgord, un antiguo archidiácono de Toledo. Por lo demás, gracias al relato del franciscano Juan Gil de Zamora titulado Historia canonica ac ciuilis liber illustrium personarum, redactado en torno a 1282, y en el que está incluida la narración sobre el descubrimiento de san Ildefonso, ${ }^{64}$ conocemos las circunstancias del hallazgo de los restos "atilanianos». ${ }^{65}$

En este documento, la intención del autor no era otra, claro está, que narrar la historia del arzobispo toledano, y no la de Atilano, una figura que aparece relegada a un segundo plano. ${ }^{66}$ En él fray Juan Gil explica que las reliquias de Ildefonso se habían encontrado fortuitamente en la iglesia de San Pedro de la ciudad: «ubi sedes cathedralis fuerat, aliquando pignus sanctissimum reposuerunt ${ }^{67}$ a raíz del episodio de la huida de los últimos visigodos hacia Asturias tras la invasión musulmana del siglo VIII. Se habían quedado sepultadas en aquel lugar y olvidadas hasta el providencial hallazgo de mediados del siglo XIII. Ahora bien, resulta que junto al antiguo primado de las Españas yacía también Atilano, en el mismísimo lugar donde se ubicaba el altar de la Virgen María: «adiciens quod ibidem corpus beati Atillani, qui in eadem ecclesia pontificali functus fuerat officio, quiescebat [...] corpus sancti Atillani pontificis et beatissimi Froylani eius socii reconditum esse dicebat». ${ }^{68}$

¿Mera casualidad? No tanta si tenemos en cuenta que Atilano guardaba un lejano vínculo con Ildefonso puesto que el primero había copiado, durante su estancia monástica en Sahagún, el De perpetua virginitate sanctae Mariae, compuesto varios siglos antes por el segundo.

¿Pero qué hacía Ildefonso en la iglesia de San Pedro de Zamora y por qué no estaba en otro lugar, en un camino por ejemplo más directo entre Toledo y Asturias? De la misma manera, ¿por qué haber implicado a Atilano en la inventio ildefonsí? Para contestar a estas preguntas es preciso presentar el problema del mapa diocesano hispánico de los siglos XII y XIII, ${ }^{69}$ sabiendo que la creación, los límites y la vinculación de la diócesis de Zamora están relacionados con lo que la historiografía ha llamado, con mucha razón, el «imbroglio» zamorano. ${ }^{70}$ En este juego muy turbio y sumamente complejo, Zamora estaba constantemente zarandeada, como distrito sufragáneo, entre los arzobispados de Braga, Santiago y Toledo. A estas antiguas querellas se añadió, a mediados del siglo XIII, la reciente conquista del valle del Guadalquivir, con la restauración de Sevilla

${ }^{64}$ BN Madrid, mss. 2763, igualmente conocida con el nombre de «Historia canónica y civil».

${ }_{65}$ Gil de Zamora 2014: 152-169; cf. igualmente Fita 1885: 60-71. Se trata en realidad de una extensión hagiográfica llevada a cabo a partir de la vita Ildephonsi de Cixila.

66 Sobre este descubrimento, cf. Garcia 2007.

67 LS, p. 159.

68 Ibid., p. 160.

69 Mansilla Reoyo 1994: 92-111; Henriet 2008.

70 Fletcher 1978: 195-203 y 1994: 474, «La solución más prudente hubiera sido declarar a Zamora sede exenta, como Burgos, León y Oviedo. Pero no fue así [...] es posible que la curia pontificia barajase la posibilidad de la exención». como metrópoli, ${ }^{71}$ y la consiguiente cuestión siempre delicada y en suspenso de la histórica Mérida cuyo título había sido recuperado - en realidad usurpado - por Santiago de Compostela en $1120 .^{72}$

En lo tocante a la inventio de lldefonso, hemos observado que don Suero Pérez, un hombre astuto y ambicioso como pocos, excelente conocedor por lo demás de las intrigas de la curia de Alfonso $\mathrm{X}^{73}$ a quien siguió en el séquito regio durante varios años como canciller del reino de León, supo sacar provecho del contexto espacio-temporal aludido para imponer la exención ${ }^{74}$ de Zamora respecto de cualquiera de las sedes metropolitanas en pugna, o sea para conseguir de cierto modo un privilegio de exención semejante al que ostentaban Oviedo y León, en resumidas cuentas para transformar su diócesis en zona neutral entre los distintos arzobispos en competencia por ella. ${ }^{75}$ Para introducir en Zamora al prestigioso metropolita de la Toledo visigoda y diseñar a orillas del Duero un importante "culto cívico ${ }^{76}$ emancipador e incuestionable, el mejor medio para el taimado obispo consistió en insertar en el relato hagiográfico a un santo local perdido en la niebla del olvido puesto que esta era la forma de actuar más acostumbrada entonces. ${ }^{77}$ En semejante contexto, ¿quién mejor que Atilano para introducir e imponer a lldefonso en una Zamora que ya lo había consagrado a él? Fue pues por mediación de un viejo recurso hagiográfico y por la elevación - de corta duración- de los dos cuerpos sobre el mismo altar de la iglesia de San Pedro que el culto hacia san Atilano salió reactivado de manera un tanto indirecta. Y fue por fin para evitar una competencia entre ambas devociones por lo que Ildefonso sería proclamado patrono de la ciudad y Atilano de la diócesis. Si se establece una comparación entre los dos protagonistas, se ve claramente que la santidad de Atilano no tiene la misma dimensión que la de Ildefonso. Así, mientras este, según la narración de Juan Gil, es el autor de numerosos milagros post-mortem, Atilano no es acreditado de dichos portentos, sencillamente porque no dejaba de ser un mero testaferro en el episodio de la inventio. Parecida relegación puede explicarse fácilmente. Al objeto de crear un culto cívico y conseguir con este la emancipación zamorana ante cualquier género de jerarquía, resultaba imprescindible poner en escena a un santo incuestionable, de categoría. Ahora bien, para el franciscano, buen conocedor del santoral, la reserva de santos prestigiosos sin sepultura conocida a finales del siglo XIII era extremadamente reducida ya que la santidad de Atilano era de origen popular - fama sanctitatis espontánea- y por lo tanto cuestionable a todos efectos.

71 «capud et metropolis tocius Hispanie» según figura en el epitafio de Fernando III.

72 Falque Rey 1988: 254-255.

73 «Además estaba Suero Pérez, obispo de Zamora (1255-86) y notario de Alfonso [X] para el reino de León, un tipo reconocible inmediatamente y un pilar episcopal, ambicioso, por naturaleza en el campo administrativo más que el intelectual» Linehan 2011: 542.

74 Linehan 1993: 515-516.

75 Garcia 2007: 237-238.

76 García de la Borbolla 2004: 51.

77 Tal es por ejemplo el caso en Zaragoza donde el santo local Valero fue utilizado para reintroducir al visigodo Braulio, o el de León, ciudad en la que el culto a san Isidoro de Sevilla se hizo por medio del santo, y canónigo, local Martino, cf. Henriet 1999; García de la Borbolla 2002: 135; Pérez-Embid Wamba 2002: 192-214. 
No había recibido la aprobación canónica formal de Roma, cosa que no ocurría, ni mucho menos, con lldefonso. ${ }^{78}$

Por razones que hemos expuesto en otro lugar, ${ }^{79}$ el culto de los dos santos no prosperó localmente durante el siglo XIV, y hubo que esperar que las circunstancias políticas cambiaran en profundidad para que su devoción volviera a resurgir, lo que efectivamente ocurrió a finales del siglo XV, y con mayor éxito aún en la Edad Moderna. ${ }^{80}$ De este periodo están efectivamente fechadas las escasas representaciones de Atilano puesto que ninguna de las que han llegado hasta nosotros es propiamente medieval. En la sillería de la catedral de Zamora, fechada entre 1502-1505, existe por ejemplo un bajorrelieve en el que se ve a Atilano mitrado con el báculo episcopal en la mano izquierda y mirando hacia el anillo que encontrara dentro del pez. ${ }^{81}$ Con excepción por consiguiente de las escasas huellas, la presencia de Atilano en la topografía de la ciudad es relativamente discreta en la actualidad. Además del cementerio ya citado, contamos con la presencia del edificio monumental del seminario mayor, que lleva el nombre del santo, y con la reciente escultura metálica colocada en el viejo puente de piedra que salva el Duero. De hecho, esta obra moderna reivindica más un homenaje al pez milagroso que al santo ya que Atilano no aparece representado en ningún momento. ${ }^{82}$ Para concluir, casualidad de las abundantes furta sacra de los tiempos pasados, cabe observar que la cabeza de san Atilano se encuentra en Toledo, ${ }^{83}$ y no en Zamora, pero esto es otra historia...

Al término de esta presentación, quisiera insistir sobre el interés que, para el historiador, presenta el análisis de las Vidas de los santos. Gracias a ellas vislumbramos por ejemplo las rivalidades entre las diócesis, las provincias metropolitanas y los monasterios, en suma, entre unas instituciones productoras de textos propagandísticos destinados a servir los intereses de quienes las encabezaban. Entre los principales medios de esta propaganda - si bien no el únicohemos podido contar con la Vida de Atilano, la cual se prestó

78 «Gloriosissimus Aldefonsus Archiepiscopus Tholetanus, fons eloquentie clarus et perspicuus, beatorum trium Doctorum supradictorum et Eugenii consanguineus [...] Atollit nichilominus Hispaniam beatissimus Legionensis Espiscopus Froylanus, super quem Spiritus Sanctus in specie columbe descendit; cuius etiam labia immissis ardentibus prunis non stuarunt. Innumerabiles quidem sunt et alii sancti in sacratissima patria procreati; ut sunt Vincentius, Sabina, Christeta, Felix, Fructuosus, Eulalia, Marina, Euphemia et alii plures, quorum sin voluero nomina tradere scriptis facilius me tempus quam copia desseret. Sed pretermitendi non sunt beatissimi Dominicus et Antonius» Gil de Zamora 1955: 149-150. Con independencia del número limitado de obispos de esta lista, se observará la ausencia notable de Atilano al que Juan Gil no cita para nada en su obra. De la misma manera, se notará que la mayoría de los santos citados son posteriores a 711, lo que significa que no habían recibido la sanción oficial de la Santa Sede por lo que se les consideraba entonces, p. 151: «Fuerunt alie persone famosissime in Hispania, que anthonomasice Christi Ecclesiam decorarunt, licet non fuerint ascripte cathalogo sanctorum» Pérez-Embid Wamba 2002: 344.

79 Garcia 2007.

80 Bécares Botas 1990.

81 Teijeira Pablos 1996: 71.

82 "La leyenda de San Atilano sobre el puente de Piedra», La Opinión de Zamora, 8 de noviembre de 2013.

83 Rojas Villandrando 2005: 74. estupendamente para reescribir el pasado bajo el pretexto de una fidelidad a la tradición de los orígenes remotos del santo. Por lo demás, el papel ejemplarizante del padre por antonomasia, pastor de su rebaño, sirvió para reformar y corregir las costumbres de la sociedad. Así pues, los diferentes documentos que hemos visto, vitae o diplomas, son un excelente reflejo de los intereses que dichos textos pretendían defender, concretamente los de León, Oviedo, Zamora y Moreruela en el marco de unas fechas bastante alejadas entre sí puesto que abarcan del siglo X al XIII.

\section{FUENTES}

Bécares Botas, Vicente. 1990. Los patronos de Zamora san Ildefonso y san Atilano. Documentación inédita. Zamora: Archivo Histórico Diocesano.

Cavero Domínguez, Gregoria y Encarnación Martín López. 1999. Colección documental de la catedral de Astorga. I (646-1126). León: Centro de estudios e investigación San Isidoro.

Escalona, Romualdo. 1782. Historia del Real monasterio de Sahagún. Madrid.

Falque Rey, Emma. 1988. Historia compostellana. Corpus Christianorum. Continuatio Mediaeualis, LXX. Turnhout: Brepols.

Fernández Duro, Cesáreo. 1882-1883. Memorias históricas de la ciudad de Zamora, su provincia y obispado, 4 t. Madrid: Rivadeneyra.

Gil de Zamora, Juan. 1955. De preconiis Hispanie, editado por Manuel de Castro y Castro. Madrid: Universidad Complutense.

Gil de Zamora, Juan. 2014. Legende sanctorum et festivitatum aliarum de quibus Ecclesia sollempnizat, lohannis Aegidii zamorensis opera omnia. II, editado por José Carlos Martín Iglesias y Eduardo Otero Pereira. Zamora: Instituto de Estudios Zamoranos Florián de Ocampo.

Gil Fernández, Juan. 2018. Chronica hispana. Saeculi VIII et IX. Corpus Christianorum. Continuatio Mediaeualis, LXV. Turnhout: Brepols.

Gil Fernández, Juan, Juan Ignacio Ruiz de la Peña y José L. Moralejo. 1985. Crónicas asturianas. Oviedo: Universidad de Oviedo.

Gutiérrez Álvarez, Maximino. 1997. Corpus inscriptionum Hispaniae Medievalium, I/1, Zamora. Turnhout: Brepols.

Mínguez Fernández, José María. 1976. Colección diplomática del monasterio de Sahagún (siglos IX y X). León: Centro de estudios e investigación San Isidoro.

Rojas Villandrando, Agustín de. 2005. Historias de Çamora y otras antigüedades, editado por Francisco Rodríguez Pascual. Zamora: Semuret.

Ruiz Asencio, José Manuel e Irene Ruiz Albi. 2007. Colección documental del monasterio de San Pedro de Eslonza. I (912-1300). León: Centro de estudios e investigación San Isidoro.

Sáez, Emilio. 1987. Colección documental del archivo de la catedral de León, I (775-952). León: Centro de estudios e investigación San Isidoro.

Sáez Emilio y Carlos Sáez. 1996. Colección diplomática del monasterio de Celanova, I (842-942). Alcalá de Henares: Universidad de Alcalá de Henares.

Sánchez Alonso, Benito. 1924. Crónica del obispo don Pelayo. Madrid: Centro de Estudios Históricos.

VA= Flórez, Enrique. 2004. "Vita Sancti Attilani episcopi zamorensis». En España Sagrada. XIV Iglesias sufragáneas de Mérida, 463-465. Madrid: Editorial revista agustiniana.

VF= Martín Iglesias, José Carlos. 2009. "La Vita Froilanis episcopi Legionensis (BHL 3180) (s. X): introducción, edición crítica y particularidades lingüísticas». En Parva pro magnis munera. Études de littérature tardo-antique et médiévale offertes à François Dolbeau par ses élèves, editado por Monique Goullet, 561-584. Turnhout: Brepols.

Yepes, Antonio de. 1960. Crónica general de la orden de San Benito, 4 t. Madrid: BAE. 


\section{Bibliografía}

Aldea Vaquero, Quintín, Tomás Marín Martínez y José Vives Gatell. 1972. Diccionario de historia eclesiástica de España, I A-C. Madrid: CSIC.

Álvarez Martínez, Ursicino. 1965. Historia general civil y eclesiástica de la provincia de Zamora. Madrid: P. López.

Andrade Cernadas, José Miguel, Marta Díaz Tie y Francisco Javier Pérez Rodríguez. 1995. O Tombo de Celanova. Santiago de Compostela: Consello da cultura galega.

Ayala Martínez, Carlos de. 2008. Sacerdocio y Reino en la España Altomedieval. Iglesia y poder político en el Occidente peninsular, siglos VII-XII. Madrid: Sílex.

Bonnaz, Yves. 1987. Les chroniques asturiennes à la fin du IXe siècle. París: CNRS.

Bouza Brey, Fermín. 1971. "Lauda sepulcral de Nausto, obispo de Coimbra». En Estudios sobre la monarquía asturiana, 275-286. Oviedo: Instituto de Estudios Asturianos.

Calderón Medina, Inés. 2008. «El impulso nobiliario a la expansión del Císter en el reino de León. La parentela de Ponce de Cabrera en los monasterios de Santa María de Moreruela y San Esteban de Nogales». Medievalismo 18: 341-374.

Canal Sánchez-Pagín, José María. 1993. «San Froilán obispo de León. Ensayo biográfico». Hispania Sacra 45: 113-146.

Carriedo Tejedo, Manuel. 1999. «Episcopologio zamorense del siglo X». Anuario de estudios zamoranos Florián de Ocampo 16: 347-365.

Doignon, Jean. 1976. "Tobie et le poisson dans la littérature et l'iconographie occidentales (III ${ }^{\mathrm{e}} \mathrm{V}^{\mathrm{e}}$ siècle). Du symbolisme funéraire à une exégèse christique». Revue de l'histoire des religions CXC (2): 113-126. https://doi.org/10.3406/rhr.1976.6354

Fernández Conde, Francisco Javier. 2008, La religiosidad medieval en España. Alta Edad Media (siglos VII-X). Gijón: Trea.

Fita, Fidel. 1885. «Traslación e invención del cuerpo de san Ildefonso. Reseña histórica por Gil de Zamora». Boletín de la Real Academia de la Historia VI: 60-71.

Fletcher, Richard A. 1978. The Episcopate in the Kingdom of León in the Twelfth Century. Oxford: Oxford University press.

Fletcher, Richard A. 1994. "Las Iglesias del reino de León y sus relaciones con Roma en la alta Edad Media hasta el concilio IV de Letrán de 1215». En El reino de León en la alta Edad Media VI, 459-495. León: Centro de estudios e investigación San Isidoro.

Garcia, Charles. 2007. «De Tolède à Zamora, l'errance des reliques de saint Ildephonse». Cahiers d'Études Hispaniques Médiévales 30: 231-259.

Garcia, Charles. 2010. "Violences et appropriation de l'espace dans I'Occident péninsulaire ibérique (XI'-XIII siècles) : le diocèse, un territoire conflictuel ?». En De l'espace aux territoires. La territorialité des processus sociaux et culturels au Moyen Âge, editado por Stéphane Boissellier, 237-260. Turnhout: Brepols.

Garcia, Charles. 2014. «Hagiographie et historicité: l'écriture de I'histoire des martyrs de Ledesma au XIII ${ }^{\mathrm{e}}$ siècle». e-Spania [En línea] 19, octubre.

García de la Borbolla, Ángeles. 2002. "La praesentia» y la «virtus»: la imagen y la función del santo a partir de la hagiografía castellanoleonesa del siglo XIII. Silos: Abadía de Silos.

García de la Borbolla, Ángeles. 2004. «La santidad episcopal y el culto cívico. Algunas notas trasmitidas por los relatos hagiográficos del siglo XIII». En La imagen del obispo hispano en la Edad Media, editado por Martín Aurell y Ángeles García de la Borbolla, 37-59. Pamplona: Universidad de Navarra, EUNSA.

Henriet, Patrick. 1999. «Un exemple de religiosité politique: Saint Isidore et les rois de León (XI $-\mathrm{XIII}$ e siècles)». En Fonctions sociales et politiques du culte des saints dans les sociétés de rite grec et latin au Moyen Âge et à l'Époque moderne. Approche comparative, editado por Marek Derwich y Michel Dmitriev, 77-95. Wroclaw: Larhcor.
Henriet, Patrick. 2007. «Heurs et malheurs de I’hagiographie épiscopale dans I'Hispania des $\mathrm{VII}^{\mathrm{e}}-\mathrm{XII}{ }^{\mathrm{e}}$ siècles». En Pratiques hagiographiques dans l'Espagne du Moyen Âge et du Siècle d'Or, editado por Amaia Arizaleta et al., II, 313-326. Toulouse: Université de Toulouse.

Henriet, Patrick. 2008. "Territoires, espaces symboliques et "frontières naturelles". Remarques sur la carte diocésaine hispanique du XII siècle». En L'espace du diocèse. Genèse d'un territoire dans l'Occident médiéval ( $V^{e}-X I I l^{e}$ siècle), dirigido por Florian Mazel, 287-307. Rennes: Presses universitaires.

Henriet, Patrick. 2009. "Écrire I’histoire des évêques en Péninsule ibérique de l'époque wisigothique à la "normalisation" de l'Église (VII $-\mathrm{XII}$ siècle)». En Liber, Gesta, histoire. Écrire l'histoire des évêques et des papes de l'Antiquité au XXI siècle, editado por François Bougard y Michel Sot, 329-346. Turnhout: Brepols.

Henriet, Patrick. 2017. "Quod recte prophetia dicitur. Introduction». En Hagiographie et prophétie (VIe-XIII siècles), editado por Patrick Henriet, Klaus Herbers y Hans-Christian Lehner, 3-13. Florencia: Sismel-Galluzzo.

Linehan, Peter. 1993. History and the Historians of medieval Spain. Oxford: Clarendon Press. [2011. Historia e historiadores de la España medieval. Salamanca: Universidad].

Linehan, Peter y José Carlos de Lera Maíllo. 2003. Las postrimerías de un obispo Alfonsino: Don Suero Pérez, el de Zamora. Zamora: Semuret.

Lucas Álvarez, Manuel. 1998. Tumbo A de la catedral de Santiago. Santiago: Cabildo de la SAMI catedral.

Luis Corral, Fernando. 2009. "Atila, Ildefonso y el obispado de Zamora». En ¿Tiempos oscuros? Territorio y sociedad en el centro de la Península ibérica, editado por Iñaki Martín Viso, 203-227. Madrid: Sílex.

Maíllo Salgado, Felipe. 1990. Zamora y los zamoranos en las fuentes arábigas medievales. Salamanca: Universidad de Salamanca.

Mansilla Reoyo, Demetrio. 1994. Geografía eclesiástica de España. Estudio histórico-geográfico de las diócesis. II. Roma: Iglesia nacional española.

Martín Viso, Iñaki. 2002. Fragmentos del Leviatán. La articulación política del espacio zamorano en la alta Edad Media. Zamora: Instituto de estudios zamoranos Florián de Ocampo.

Martínez Ángel, Lorenzo. 2005. «Reflexiones sobre las culturas oral y escrita, a propósito de una leyenda zamorana sobre San Atilano». Revista de Folklore 294: 208-211.

Mínguez Fernández, José María. 1995. «La Jornada del Foso y la frontera del Duero». En Zamora 1100 años de historia: 893-1993, coordinado por José Luis Martín, 23-33. Zamora: Ayuntamiento de Zamora.

Pérez-Embid Wamba, Javier. 2002. Hagiología y sociedad en la España medieval. Castilla y León (siglos XI-XIII). Huelva: Universidad.

Reglero de la Fuente, Carlos Manuel. 2005. El monasterio de San Isidro de Dueñas en la Edad Media. Un priorato cluniacense hispano (911-1478). León: Centro de estudios e investigación San Isidoro.

Sánchez Herrero, José. 1995. "Historia de la iglesia de Zamora. Siglos V al XV». En Historia de Zamora. I. De los orígenes al final del Medievo, coordinado por Juan Carlos Alba López, 687-753. Zamora: Diputación Provincial.

Sánchez-Albornoz, Claudio. 1972-1975. Orígenes de la nación española, III. Oviedo: Instituto de estudios asturianos.

Schmitt, Jean-Claude. 2001. "Le sujet du rêve». En Le corps, les rites, les rêves, le temps. Essais d'anthropologie médiévale, editado por Jean-Claude Schmitt, 295-315. París: Gallimard.

Teijeira Pablos, María Dolores. 1996. Juan de Bruselas y la sillería coral de la catedral de Zamora. Zamora: Instituto de estudios zamoranos Florián de Ocampo.

Vauchez, André. 1999. Saints, prophètes et visionnaires. Le pouvoir surnaturel au Moyen Âge. París: Albin Michel. 